\title{
Representative Commodity for Six Leafy Vegetables Based on the Determination of Six Pesticide Residues by Gas Chromatography
}

\author{
Shiming Song ${ }^{\dagger}$, Huili Huang ${ }^{\dagger}$, Zhaojie Chen, Jie Wei, Cheng Deng, Huihua Tan and Xuesheng Li* \\ Institute of Pesticide and Environmental Toxicology, Guangxi Key Laboratory Cultivation Base of \\ Agro-Environment and Agro-Product Safety, Guangxi University, Nanning 530005, China
}

Received: 03 July 2017; accepted: 25 July 2017

\begin{abstract}
A residue analytical method was developed for the determination of trichlorfon, chlorpyrifos, dimethoate, $\beta$ cypermethrin, deltamethrin, and chlorothalonilin in six leafy vegetables by gas chromatography-electron capture detector (GC-ECD) and gas chromatography-flame photometric detector (GC-FPD). The method had a good linearity $\left(R^{2} \geq 0.9924\right)$ and precision (RSD $\leq 14.0 \%$ ). The limits of quantification (LOQ) of six pesticides were all $0.01 \mathrm{mg} / \mathrm{kg}$. Average recoveries of six pesticides ranged from $81 \%$ to $119 \%$. The developed method was successfully applied to study the initial deposits, degrade characteristics, and terminal residues for six pesticides applied to six leafy vegetables under the same dose of formulation. The half-life of six pesticides was in the range of 0.8-8.8 days. The highest initial deposits, maximal residues, and terminal residues were found on leaf mustard and sweet potato leaves as the same pesticides were applied in different crops. Therefore, leaf mustard can be selected as representative commodity in the same subgroup to realize the residual extrapolation. This conclusion should be considered as a complement on crop classification of China.
\end{abstract}

Keywords: Leafy vegetables, six pesticides, representative commodity, residues, GC-ECD, GC-FPD

\section{Introduction}

There are always no pesticides available for use in minor crops because there is limited cultivating area and pesticide registration. In order to control the occurrence of pathogens, pests, and weeds, a large amount of pesticides was used to confirm the quality and yield [1]. However, pesticide residues in minor crop may pose a potential threat to human health for widely and violating Good Agricultural Practice (GAP) use of pesticides [2]. Residual extrapolation refers to the available method and field test results of residues, and the residual data directly extrapolated to the no field experiment is conducted in the commodity group or subgroup by using the residues on one or more representative commodities [3]. Moreover, residual extrapolation is an effective way to accelerate the registration and management of pesticide on the crops and accelerate the supplement and perfection of different countries' or regions' pesticide residual data set [4]. In the crop of leafy vegetables, cabbage and kale are regarded as registered crop in most countries $[5,6]$. However, the residual behavior difference between cabbage/kale and other leafy vegetables have never been reported. Therefore, the representative commodities, which had been selected in different countries need to be credible.

Six leafy vegetables, including cabbage (Brassica camperstris ssp. pekinens), flowering Chinese cabbage (Brassica campestris L., var. parachinensis [Bailey] Sinsk), leaf mustard (Brassica juncea [Linnaeus] Czernajew var. foliosa L. H. Bailey), leaf lettuce (var. ramosa Hort), water spinach (Ipomoea aquatica Forsk), and sweet potato leaves (Ipomoea batatas [L.] Poir) are the main edible tender leaves and tender stems of fast-growing vegetables [7], and the crop diagram of them was listed in Figure 1. Meanwhile, more than 800 pesticides are widely used in agricultural experiments to control pathogens and pests $[8,9]$. There are different group classifications of leafy vegetables in

\footnotetext{
* Author for correspondence: 1xsnngx@163.com

$\dagger$ S. S. and H. H. contributed equally to this study and share first authorship.
}

different countries and regions. In China, cabbage belongs to head brassica subgroup [10], which is similar with America [11] and European Union (EU) [12], while Japan [13] and Codex Alimentarius Commission (CAC) [14] are not having this subgroup. In China and America, flowering Chinese cabbage and leaf mustard belong to stem brassica subgroup, but EU, CAC, and Japan are not having this subgroup. Leaf lettuce and water spinach are the leafy green subgroup in China, America, and Japan, while the EU and CAC are not having this subgroup. Sweet potato leaves were not in crop classification of China, but for convenience research, sweet potato leaves were attached to leafy green vegetable subgroup. Furthermore, cabbage or kale was selected as representative commodity in head and stem brassica in China. While spinach was selected as representative commodity in leafy green subgroup. Leafy vegetables are grown commercially and consumed worldwide, and they are low in calories [15] and rich in vitamins, minerals, and phytonutrients [16]. Thus, leafy vegetables have an irreplaceable role in China and all over the world.

Trichlorfon, chlorpyrifos, and dimethoate are organophosphorus pesticides and used to control a wide range of pests on vegetables [17-19]. $\beta$ Cypermethrin and deltamethrin are pyrethroids pesticides and used to control lepidoptera pests [20] and a wide range of pests on vegetables [21], respectively. Chlorothalonil is organochlorine pesticides and used to control the fungal disease in vegetables [22]. All these pesticides are registered and widely used on vegetables in China. However, there are little data about residue behavior of six pesticides having potential to be applied for the protection of six minor crops.

The residual and risks of pesticides in six leafy vegetables above are unknown after applied. In this study, the purpose was to develop a residue analytical method using gas chromatographyelectron capture detector (GC-ECD) for $\beta$ cypermethrin, deltamethrin, and chlorothalonil, and gas chromatography-flame photometric detector (GC-FPD) for trichlorfon, chlorpyrifos, and dimethoate in six leafy vegetables. With this method, the

This is an open-access article distributed under the terms of the Creative Commons Attribution-NonCommercial 4.0 International License (https://creativecommons.org/licenses/by-nc/4.0/), which permits unrestricted use, distribution, and reproduction in any medium for non-commercial purposes, provided the original author and source are credited, a link to the CC License is provided, and changes - if any - are indicated. 

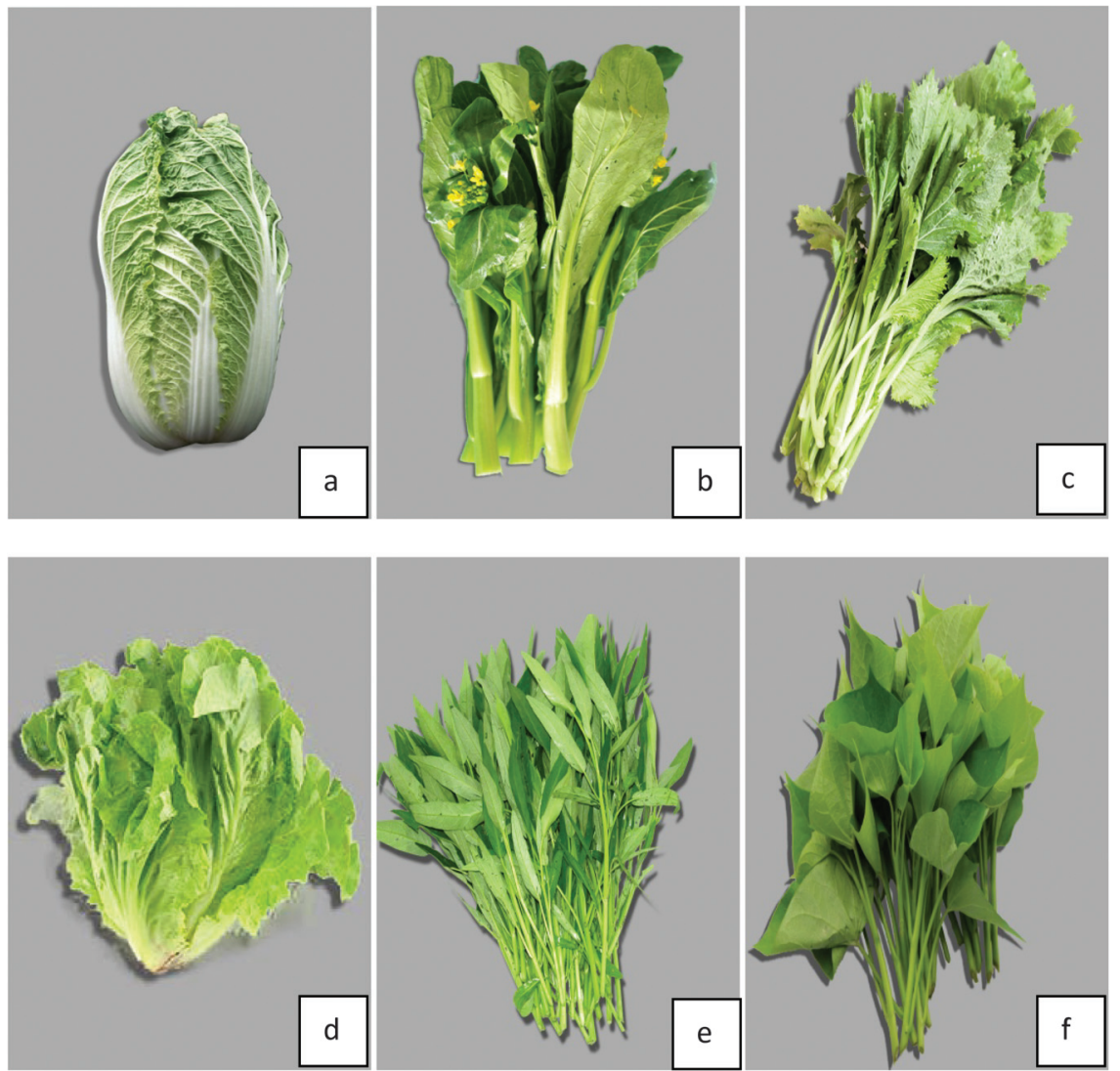

Figure 1. The crop diagram of six leafy vegetables: (a) cabbage; (b) flowering Chinese cabbage; (c) leaf mustard; (d) leaf lettuce; (e) water spinach; and (f) sweet potato leaves

determination and dissipation of trichlorfon, chlorpyrifos, dimethoate $\beta$ cypermethrin, deltamethrin, and chlorothalonil in six leafy vegetables were investigated. A suitable representative commodity for leafy vegetables group was selected based on consideration of six pesticide residues and dissipation in six leafy vegetables.

\section{Experimental}

2.1. Chemicals and reagents. Trichlorfon (97.0\%), chlorpyrifos $(98.5 \%)$, dimethoate $(98.5 \%), \quad \beta \quad$ cypermethrin (98.5\%), deltamethrin (98.0\%), and chlorothalonil (99.5\%) standard materials were purchased from Dr. Ehrenstorfer, Germany. Trichlorfon soluble powder $(90 \%)$ was purchased from Nanning Chemical Industry Co. Ltd. (Nanning, China). Dimethoate emulsifiable concentrate $(40 \%)$ was purchased from Kunming Pesticide Co. Ltd. (Kunming, China). Chlorpyrifos emulsifiable concentrate (480 g/L) was purchased from Dow Agro Sciences LLC (Pleass, IN, USA). Chlorothalonil wettable powder (75\%) was purchased from Syngenta Crop Protection Co. Ltd. (Suzhou, China). Deltamethrin emulsifiable concentrate $(25 \mathrm{~g} / \mathrm{L})$ was purchased from Bayer Crop Science (China). $\beta$ Cypermethrin microemulsion $(4.5 \%)$ was purchased from Institute of Plant Protection, Chinese Academy of Agricultural Science. $n$-Hexane (HPLC grade) was purchased from CNW Technologies $\mathrm{GmbH}$, Germany. Analytical grade sodium chloride, anhydrous magnesium sulphate, acetonitrile, acetone, dichloromethane, formic acid, diatomite, and neutral alumina were purchased from Tianjin kemi'ou Reagent Co. Ltd. (Tianjin, China). Activated carbon was purchased from Taishan Chemical Company (Taishan, China).

2.2. Field trails design and sampling. Complied with the "Standard of Practice for Field Trials of Pesticide Registration Residue" [23] and "Guideline on Pesticide Residue Trials" [24], the dissipation and final residue experiments (three replicates) were conducted in Nanning (Guangxi province, field location:
N $22^{\circ} 50^{\prime} 57.23^{\prime \prime}$, E $108^{\circ} 17^{\prime} 20.28^{\prime \prime}$ ) on September to December 2014. The average temperature of 4 months was 27 ${ }^{\circ} \mathrm{C}, 24{ }^{\circ} \mathrm{C}, 21{ }^{\circ} \mathrm{C}$, and $14{ }^{\circ} \mathrm{C}$, respectively. The average precipitation was $3.3 \mathrm{~mm}, 1.3 \mathrm{~mm}, 2.9 \mathrm{~mm}$, and $2.9 \mathrm{~mm}$, respectively. The experimental area was designed with one test plot and a control plot without pesticides treatment. For the dissipation experiment and the final residue experiment, the area of experimental plot was $30 \mathrm{~m}^{2}$. A buffer area was employed to separate each plot. The dosage (highest recommended dosage) application was shown in Table 1 . Approximately $1 \mathrm{~kg}$ sample was collected randomly from five points in each plot at intervals of $2 \mathrm{~h}, 1,3,5,7,14$, and 21 days after applied to dissipation experiment. As to terminal residue experiment, the interval of application was 7 days, and about $1 \mathrm{~kg}$ samples were collected in each plot at 3, 7, 14, and 21 days after application. All samples were cut into pieces and homogenized and then stored at $-20{ }^{\circ} \mathrm{C}$ in the freezer and analyzed within a month.

2.3. GC analysis. Trichlorfon, chlorpyrifos, and dimethoate were analyzed by GC-FPD (Agilent GC 7890A) equipped with aDB-1701 capillary column $(30 \mathrm{~m} \times 0.25 \mathrm{~mm} \times 0.25 \mu \mathrm{m})$. Nitrogen $(1 \mathrm{~mL} / \mathrm{min})$, hydrogen $(60 \mathrm{~mL} / \mathrm{min})$, and air $(80 \mathrm{~mL} / \mathrm{min})$ were used as carrier gas. The temperature of injection port was $250{ }^{\circ} \mathrm{C}$, and $1 \mu \mathrm{L}$ of each sample was injected in splitless mode.

Table 1. The actual applying pesticide dose of six pesticides

\begin{tabular}{lccc}
\hline Pesticides & \multicolumn{2}{c}{ Supply times } & $\begin{array}{c}\text { Dose } \\
\text { (g a.i./ha) }\end{array}$ \\
\cline { 2 - 3 } & Dynamic & Terminal residues & 1620 \\
\hline Trichlorfon & 1 & 3 & 600 \\
Dimethoate & 1 & 3 & 600 \\
Chlorpyrifos & 1 & 3 & 3000 \\
Chlorothalonil & 1 & 3 & 22.5 \\
$\beta$ Cypermethrin & 1 & 3 & 54 \\
Deltamethrin & 1 & 3 & \\
\hline
\end{tabular}


The temperature of detector was $250{ }^{\circ} \mathrm{C}$, the column temperature was initially at $60{ }^{\circ} \mathrm{C}$ for $2 \mathrm{~min}$, raised to $250{ }^{\circ} \mathrm{C}$ at $20{ }^{\circ} \mathrm{C} / \mathrm{min}$, and then held at that temperature for $7 \mathrm{~min}$. The retention time of trichlorfon, chlorpyrifos, and dimethoate was $5.60 \mathrm{~min}, 12.76 \mathrm{~min}$, and $13.30 \mathrm{~min}$, respectively.

$\beta$ Cypermethrin, deltamethrin, and chlorothalonil were analyzed by GC-ECD (Agilent GC 7890A) equipped with a HP-5 capillary column $(30 \mathrm{~m} \times 0.25 \mathrm{~mm} \times 0.25 \mu \mathrm{m})$. Nitrogen (purity $99.9995 \%$ ) was used as carrier gas at a constant flow rate of $1 \mathrm{~mL} / \mathrm{min}$. The temperature of injection port was $260{ }^{\circ} \mathrm{C}$, and $1 \mu \mathrm{L}$ of each sample was injected in splitless mode. The temperature of detector was $310^{\circ} \mathrm{C}$, the column temperature was initially at $150{ }^{\circ} \mathrm{C}$ for $2 \mathrm{~min}$, raised to $270{ }^{\circ} \mathrm{C}$ at $10{ }^{\circ} \mathrm{C} / \mathrm{min}$, and then held at that temperature for $15 \mathrm{~min}$. The retention time of chlorothalonil was $8.97 \mathrm{~min}$, and $\beta$ cypermethrin was $19.07 \mathrm{~min}$. Deltamethrin had two peaks with retention times of 22.48 and $23.16 \mathrm{~min}$, and sum area of the two peaks was used in quantification of deltamethrin.

For screening, $0.05 \mathrm{~mL}$ of sample was transferred into an autosampler vial containing $0.95 \mathrm{~mL}$ of acetone (organophosphorus) or $n$-hexane (organochlorine). Then, sample screening analysis was performed. Based on the screening result, the sample was diluted as needed. A portion of the sample was transferred and filtered using a $0.2 \mu \mathrm{m}$ PTFE syringe filter into an autosampler vial. After that, sample analysis was performed.

2.4. Sample extraction and purification. Sample extraction was carried out by improving the method of NY/T761-2008 [25]. Blank samples were used for validation studies and matrixmatched standard calibrations. Twenty grams of homogenized sample was weighed in a $100 \mathrm{~mL}$ Teflon centrifuge tube, and $40 \mathrm{~mL}$ of $1 \%$ formic acid in acetonitrile was added. Each sample was extracting with vibration for $20 \mathrm{~min}$. Then, the $100 \mathrm{~mL}$ Teflon centrifuge tube was centrifuged to $4500 \mathrm{r} / \mathrm{min}$ for $5 \mathrm{~min}$, and all of the supernatants were transferred into a $50 \mathrm{~mL}$ Teflon centrifuge tube, which contains $7 \mathrm{~g}$ sodium chloride. And then vortexed for $1 \mathrm{~min}$ and centrifuged to 4500 $\mathrm{r} / \mathrm{min}$ for $5 \mathrm{~min}$ with $50 \mathrm{~mL}$ tube. Finally, the supernatant of $\beta$ cypermethrin, deltamethrin, and chlorothalonil was filtered through a $0.22 \mu \mathrm{m}$ membrane into autosampler vials for GC-ECD analysis, while trichlorfon, chlorpyrifos, and dimethoate were needed to purification.

The glass chromatography column, the inner diameter and length of which was $1 \mathrm{~cm}$ and $16 \mathrm{~cm}$, respectively, was adopted to purification, and three layers of material were included. The top layer was $2.0 \mathrm{~g}$ anhydrous sodium sulfate. The middle layer was the mixture of $1.0 \mathrm{~g}$ diatomite and $0.5 \mathrm{~g}$ activated carbon, which were dissolved by dichloromethane, while the bottom layer was also $2.0 \mathrm{~g}$ anhydrous sodium sulfate. About $10 \mathrm{~mL}$ dichloromethane was used to preleach, and $5 \mathrm{~mL}$ supernatant was transferred into the column. Then, $4 \times 10 \mathrm{~mL}$ dichloromethane was employed to elute, and the elution was evaporated to dryness below $42{ }^{\circ} \mathrm{C}$; thereafter, the residue was dissolved in $2.5 \mathrm{~mL}$ of acetone and filtered through a $0.22 \mu \mathrm{m}$ filter membrane into autosampler vials for GC-FPD analysis.

2.5. Standard solution preparation. Individual pesticide stock solutions, which contains $1000 \mathrm{mg} / \mathrm{L}$ of standard compounds, were prepared in acetone (trichlorfon, chlorpyrifos, and dimethoate) and $n$-hexane ( $\beta$ cypermethrin, deltamethrin, and chlorothalonil) and stored at $-20{ }^{\circ} \mathrm{C}$. Mixture of trichlorfon, chlorpyrifos, and dimethoate were prepared in acetone, while $\beta$ cypermethrin, deltamethrin, and chlorothalonil were prepared in $n$-hexane. Working standard solution was prepared by diluting the mixture of stock solutions with matrix to obtain concentrations of $0.01,0.05,0.1,0.5$, and $1 \mathrm{mg} / \mathrm{L}$.

2.6. Statistical method. The plotting of residue concentration and time was used to determine the dissipation kinetics of pesticides in six leafy green vegetables. The dissipation and half- life $\left(t_{1 / 2}\right)$ was calculated by the first-order rate equation. The firstorder kinetics are confirmed further by performing graphically from the equation of $C_{t}=C_{0} e^{-k t}$, where $C_{t}$ represents the concentration of the pesticide residue at time $t, C_{0}$ represents the initial concentration after application, and $k$ is the degradation rate constant in per day. The half-life $\left(t_{1 / 2}, t_{1 / 2}=\ln (2) / k\right)$ is calculated from the $k$ value for each experiment. To find out the significant differences $(p<0.05)$ of residues in six leafy vegetables, statistical tests (Duncan test) were applied by IBM SPSS Statistics 19.0.

\section{Results and discussion}

3.1. Method validation. Quantification of sample extracts during validation was done using a calibration curve on matrixmatched standard calibration method. Good linearity was achieved in the range of $0.01-1 \mathrm{mg} / \mathrm{L}$ with five calibration points $(0.01,0.05,0.1,0.5$, and $1 \mathrm{mg} / \mathrm{L})$. The correlation coefficient $\left(R^{2}\right)$ was $0.9924-1$. The limits of quantification (LOQ) at a signal-to-noise ratio $(S / N)$ of 10 for six pesticides were all $0.01 \mathrm{mg} / \mathrm{kg}$. All data are shown in Table 2.

The analytical method described earlier was evaluated by recoveries of six pesticides at three spiked levels with $0.01 \mathrm{mg} / \mathrm{kg}$, $0.05 \mathrm{mg} / \mathrm{kg}$, and $0.5 \mathrm{mg} / \mathrm{kg}$. For each spiked level, five replicated samples were analyzed. The average recoveries of $\beta$ cypermethrin, deltamethrin, chlorothalonil, trichlorfon, chlorpyrifos, and dimethoate were in the range of $81-112 \%, 81-110 \%, 82-114 \%$,

Table 2. The standard curve equation, correlation coefficient, linear range of matrix matching standard solution in six pesticides

\begin{tabular}{|c|c|c|c|}
\hline Matrix & Standard curve equation & $R^{2}$ & $\begin{array}{c}\text { Linear range } \\
(\mathrm{mg} / \mathrm{kg})\end{array}$ \\
\hline \multicolumn{4}{|l|}{ Trichlorfon } \\
\hline Cabbage & $y=2152.9 x-61.229$ & 0.998 & $0.01-1$ \\
\hline Flowering Chinese cabbage & $y=2473.4 x-51.837$ & 0.999 & \\
\hline Leaf mustard & $y=2024.6 x-36.216$ & 0.998 & \\
\hline Leaf lettuce & $y=1521.2 x+27.192$ & 0.992 & \\
\hline Water spinach & $y=1753.6 x-26.253$ & 0.998 & \\
\hline Sweet potato leaves & $y=1968.3 x-55.197$ & 0.998 & \\
\hline \multicolumn{4}{|l|}{ Dimethoate } \\
\hline Cabbage & $y=6223.9 x-54.118$ & 0.999 & $0.01-1$ \\
\hline Flowering Chinese cabbage & $y=7113.8 x+16.236$ & 1.000 & \\
\hline Leaf mustard & $y=5818.8 x-77.352$ & 0.999 & \\
\hline Leaf lettuce & $y=6060.1 x+39.059$ & 1.000 & \\
\hline Water spinach & $y=5350.5 x+25.543$ & 0.999 & \\
\hline Sweet potato leaves & $y=8355.1 x-75.951$ & 0.999 & \\
\hline \multicolumn{4}{|l|}{ Chlorpyrifos } \\
\hline Cabbage & $y=9936.5 x-182.86$ & 0.999 & $0.01-1$ \\
\hline Flowering Chinese cabbage & $y=10,533 x-269.40$ & 0.995 & \\
\hline Leaf mustard & $y=10,020 x-169.96$ & 0.999 & \\
\hline Leaf lettuce & $y=9626.1 x-9.6101$ & 0.996 & \\
\hline Water spinach & $y=7969.1 x-26.860$ & 1.000 & \\
\hline Sweet potato leaves & $y=10,722 x-198.68$ & 0.997 & \\
\hline \multicolumn{4}{|l|}{ Chlorothalonil } \\
\hline Cabbage & $y=14,982 x+214.41$ & 0.996 & $0.01-1$ \\
\hline Flowering Chinese cabbage & $y=30,438 x-911.43$ & 0.991 & \\
\hline Leaf mustard & $y=16,900 x-128.10$ & 0.999 & \\
\hline Leaf lettuce & $y=21,180 x+122.19$ & 1.000 & \\
\hline Water spinach & $y=20,819 x+125.1$ & 0.994 & \\
\hline Sweet potato leaves & $y=42,020 x-121.04$ & 0.997 & \\
\hline \multicolumn{4}{|l|}{$\beta$ cypermethrin } \\
\hline Cabbage & $y=45,897 x-351.50$ & 0.999 & $0.01-1$ \\
\hline Flowering Chinese cabbage & $y=74,763 x-1226.4$ & 0.997 & \\
\hline Leaf mustard & $y=40,690 x-273.52$ & 1.000 & \\
\hline Leaf lettuce & $y=40,865 x-462.65$ & 0.999 & \\
\hline Water spinach & $y=60,372 x+441.42$ & 1.000 & \\
\hline Sweet potato leaves & $y=78,605 x-1019.1$ & 0.999 & \\
\hline \multicolumn{4}{|l|}{ Deltamethrin } \\
\hline Cabbage & $y=28,082 x-39.107$ & 1.000 & $0.01-1$ \\
\hline Flowering Chinese cabbage & $y=67,558 x-1221.9$ & 0.997 & \\
\hline Leaf mustard & $y=23,573 x-133.64$ & 1.000 & \\
\hline Leaf lettuce & $y=23,282 x-304.42$ & 0.999 & \\
\hline Water spinach & $y=25,863 x-239.5$ & 1.000 & \\
\hline Sweet potato leaves & $y=69,436 x-1024.3$ & 0.999 & \\
\hline
\end{tabular}


Representative Commodity for Six Leafy Vegetables

Table 3. The average recoveries and relative standard deviation of six pesticides in leafy vegetables with three spike levels

\begin{tabular}{|c|c|c|c|c|c|c|c|}
\hline \multirow[t]{2}{*}{ Matrix } & \multirow{2}{*}{$\begin{array}{l}\text { Spike level } \\
(\mathrm{mg} / \mathrm{kg})\end{array}$} & \multicolumn{6}{|c|}{ Recovery, \% (RSD, \%) $(n=5)$} \\
\hline & & Trichlorfon & Dimethoate & Chlorpyrifos & Chlorothalonil & $\beta$ Cypermethrin & Deltamethrin \\
\hline \multirow[t]{3}{*}{ Cabbage } & 0.01 & $100(2)$ & $85(9)$ & $116(3)$ & $114(10)$ & $89(10)$ & $88(5)$ \\
\hline & 0.05 & $90(7)$ & $92(11)$ & $110(7)$ & $92(5)$ & $88(6)$ & $84(9)$ \\
\hline & 0.5 & $92(11)$ & $81(3)$ & $88(5)$ & $100(8)$ & $82(8)$ & $81(7)$ \\
\hline \multirow[t]{3}{*}{ Flowering Chinese cabbage } & 0.01 & $94(9)$ & $109(10)$ & $119(4)$ & $106(13)$ & $104(8)$ & $94(10)$ \\
\hline & 0.05 & $98(8)$ & $100(12)$ & $113(4)$ & $89(7)$ & $81(7)$ & $85(7)$ \\
\hline & 0.5 & $95(8)$ & $93(6)$ & $95(8)$ & $93(12)$ & $99(10)$ & $91(5)$ \\
\hline \multirow[t]{3}{*}{ Leaf mustard } & 0.01 & $114(8)$ & 95 (12) & $109(7)$ & $108(7)$ & $102(3)$ & $98(9)$ \\
\hline & 0.05 & $97(10)$ & $83(13)$ & $113(9)$ & $111(7)$ & $89(8)$ & $81(4)$ \\
\hline & 0.5 & $99(8)$ & 87 (13) & $105(10)$ & $82(10)$ & $95(6)$ & $87(7)$ \\
\hline \multirow[t]{3}{*}{ Leaf lettuce } & 0.01 & 83 (13) & $85(12)$ & $100(5)$ & $99(6)$ & $112(10)$ & $110(4)$ \\
\hline & 0.05 & $107(7)$ & $97(7)$ & 109 (1) & $104(5)$ & $102(7)$ & 109 (3) \\
\hline & 0.5 & $102(8)$ & $96(6)$ & $99(5)$ & $111(10)$ & $106(11)$ & $101(9)$ \\
\hline \multirow[t]{3}{*}{ Water spinach } & 0.01 & $96(8)$ & $88(13)$ & $108(9)$ & $102(6)$ & $80(5)$ & $85(7)$ \\
\hline & 0.05 & $100(8)$ & $92(8)$ & $116(6)$ & $90(3)$ & $86(4)$ & $98(9)$ \\
\hline & 0.5 & $117(7)$ & $114(10)$ & $119(7)$ & $89(3)$ & $89(7)$ & $89(7)$ \\
\hline \multirow[t]{2}{*}{ Sweet potato leaves } & 0.01 & $81(7)$ & $85(7)$ & $117(8)$ & 104 (14) & $95(11)$ & $104(7)$ \\
\hline & 0.5 & 117 (14) & $98(9)$ & $100(9)$ & $107(7)$ & $102(9)$ & $104(8)$ \\
\hline
\end{tabular}
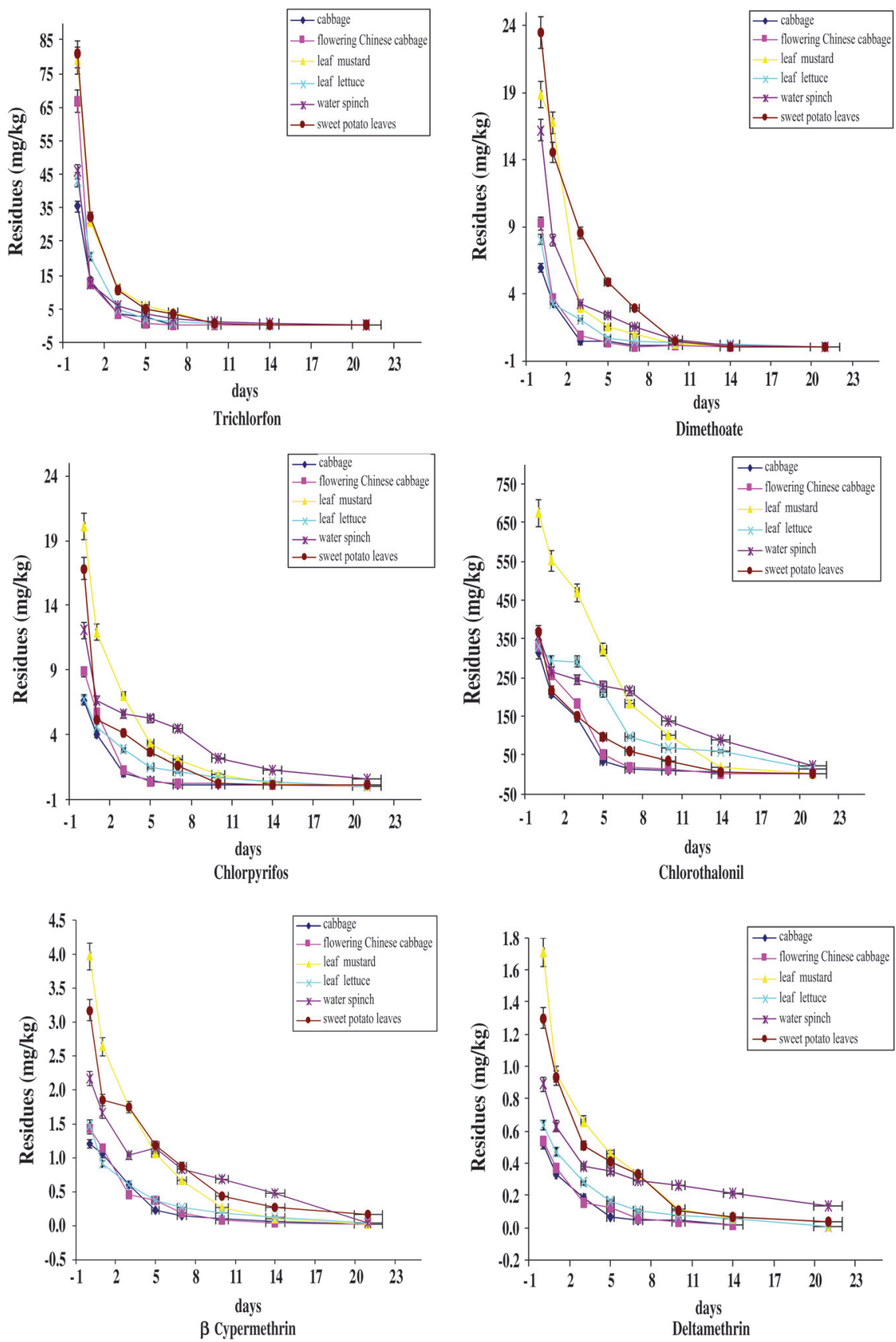

Figure 2. Dissipation curves of six pesticides in six leafy vegetables 
$81-119 \%, 88-116 \%$, and $81-114 \%$. The relative standard deviations (RSD,) were between $1 \%$ and $14 \%$. The data of average recovery and RSD are shown in Table 3 . Therefore, the developed method conforms to the requirements of China, Japan, the European Union, and other countries for the determination of pesticide residues.

3.2. Dissipation of six pesticides. The dissipation curves of six pesticides in six leafy vegetables are shown in Figure 2. The half-life $\left(t_{1 / 2}\right)$ (significant level was $\alpha=0.05, n=3$ ) and $C_{t}=C_{0} e^{-k t}$ of residue dissipation are listed in Table 4 . The $t_{1 / 2}$ of trichlorfon, dimethoate, chlorpyrifos, chlorothalonil, $\beta$ cypermethrin, and deltamethrin was in the range of 2.17-3.03 days, 0.77-2.24 days, $0.92-3.01$ days, $2.21-5.84$ days, 2.62-7.01 days, and 2.63-8.83 days, respectively. The result shows that trichlorfon, chlorothalonil, $\beta$ cypermethrin, and deltamethrin had the longest $t_{1 / 2}$ in water spinach, which was $3.03,5.84,7.01$, and 8.83 days, respectively, while dimethoate and chlorpyrifos had the longest $t_{1 / 2}$ in cabbage, which was 2.24 and 3.01 days. The shortest $t_{1 / 2}$ in trichlorfon, dimethoate, chlorothalonil, $\beta$ cypermethrin, and deltamethrin was found on flowering Chinese cabbage and was 2.17, 0.77, 2.21, 2.62, and 2.63, respectively. In addition, chlorpyrifos had the shortest $t_{1 / 2}$ in leaf mustard. On the whole, water spinach/flowering Chinese cabbage had longest/shortest $t_{1 / 2}$ in six pesticides. For the growth characteristics of water spinach/flowering Chinese cabbage, longer/shorter half-life may cause in it.

3.3. Initial deposits of six pesticides. The initial deposits (significant level was $\alpha=0.05, n=3$ ) of six pesticides in six leafy vegetables are presented in Table 5. From the results, we could gain that the highest initial deposits were found on leaf mustard for chlorpyrifos, chlorothalonil, $\beta$ cypermethrin, and deltamethrin, which were $20.1,674.1,3.98$, and $1.71 \mathrm{mg} / \mathrm{kg}$, respectively. The initial deposits of trichlorfon and dimethoate in sweet potato leaves were the highest, and the value was 80.7 and $23.44 \mathrm{mg} / \mathrm{kg}$. Leaf mustard has the highest initial deposits of six pesticides in head and stem brassica vegetable subgroup, while sweet potato leaves have the highest initial deposits of six pesticides in leafy green vegetable subgroup. Furthermore, cabbage had the least initial deposits of six pesticides, which were $35.4,5.97,6.7,314.7,1.21$, and $0.51 \mathrm{mg} / \mathrm{kg}$, respectively. Meanwhile, cabbage and leaf lettuce had the least initial deposits of six pesticides in each vegetable subgroup. It may be related to the extension of leaf mustard or sweet potato leaves and its large surface area, while the cabbage and leaf lettuce are a small area of the whole package. To summarize, leaf mustard and sweet potato leaves had highest initial deposits in six pesticides, while cabbage and leaf lettuce had least initial deposits.

3.4. Maximal residues of six pesticides. Maximum residues refer to the field after the application of pesticides, and the highest value of pesticide residues was detected in the samples. The maximum residues of six pesticides were in agreement with the initial deposits in six leafy vegetables. The maximum residues of six pesticides were all appeared at 2 hours after spray. This finding shows that leaf mustard and sweet potato leaves had the highest maximum residues after six pesticides were applied.

3.5. Terminal residues of six pesticides at four PHIs in six leafy vegetables. The half-life, initial deposits, and maximum residues would impact on terminal residue levels at specified preharvest interval (PHI). The terminal residues of six pesticides in six leafy vegetables at four PHIs of 3 days, 7 days, 14 days, and 21 days are shown in Figure 3. The terminal residues (significant level was $\alpha=0.05, n=3$ ) of six pesticides in six leafy vegetables at 7 days PHI are summarized in Table 6. The maximum residue limits (MRLs) of trichlorfon, dimethoate, chlorpyrifos, chlorothalonil, $\beta$ cypermethrin, and deltamethrin, established by China, were $0.2,1.0,5.0,2.0$, and $0.5 \mathrm{mg} / \mathrm{kg}$ respectively. With the analysis of data at four PHIs, it was found that the highest terminal residues of different pesticides had certain rules. The highest terminal residues were found on leaf mustard for chlorpyrifos, chlorothalonil, $\beta$ cypermethrin, and deltamethrin at 7 days PHI. Residues of six pesticides at 7 days

Table 4. Dissipation curve and half-life (significant level was $\alpha=0.05, n=3$ ) for six pesticides in six leafy vegetables

\begin{tabular}{|c|c|c|c|c|c|c|c|}
\hline \multirow[t]{2}{*}{ Pesticides } & & \multicolumn{6}{|c|}{ Matrix } \\
\hline & & Cabbage & $\begin{array}{c}\text { Flowering Chinese } \\
\text { cabbage }\end{array}$ & Leaf mustard & Leaf lettuce & Water spinach & $\begin{array}{c}\text { Sweet potato } \\
\text { leaves }\end{array}$ \\
\hline \multirow[t]{2}{*}{ Trichlorfon } & $\begin{array}{c}\text { Dissipation } \\
\text { equation }\end{array}$ & $C_{t}=12.711 e^{-0.318 t}$ & $C_{t}=7.7401 e^{-0.32 t}$ & $C_{t}=35.353 e^{-0.316 t}$ & $C_{t}=14.858 e^{-0.269 t}$ & $C_{t}=15.816 e^{-0.229 t}$ & $C_{t}=31.630 e^{-0.295 t}$ \\
\hline & half-life/day & $2.18^{c}$ & $2.17^{c}$ & $2.2^{c}$ & $2.58^{b}$ & $3.03^{a}$ & $2.35^{b, c}$ \\
\hline \multirow[t]{2}{*}{ Dimethoate } & $\begin{array}{l}\text { Dissipation } \\
\text { equation }\end{array}$ & $C_{t}=2.6633 e^{-309 t}$ & $C_{t}=15.040 e^{-0.895 t}$ & $C_{t}=58.915 e^{-0.893 t}$ & $C_{t}=18.659 e^{-0.793 t}$ & $C_{t}=59.739 e^{-0.896 t}$ & $C_{t}=26.550 e^{-0.399 t}$ \\
\hline & half-life/day & $2.24^{a}$ & $0.77^{c}$ & $0.78^{c}$ & $0.87^{c}$ & $0.77^{c}$ & $1.74^{b}$ \\
\hline \multirow[t]{2}{*}{ Chlorpyrifos } & $\begin{array}{l}\text { Dissipation } \\
\text { equation }\end{array}$ & $C_{t}=2.8108 e^{-0.23 t}$ & $C_{t}=11.927 e^{-0.639 t}$ & $C_{t}=60.291 e^{-0.753 t}$ & $C_{t}=16.451 e^{-0.595 t}$ & $C_{t}=18.931 e^{-0.379 t}$ & $C_{t}=29.441 e^{-0.67 t}$ \\
\hline & half-life/day & $3.01^{a}$ & $1.08^{c, d}$ & $0.92^{d}$ & $1.16^{c}$ & $1.83^{b}$ & $1.03^{c, d}$ \\
\hline \multirow[t]{2}{*}{ Chlorothalonil } & $\begin{array}{l}\text { Dissipation } \\
\text { equation }\end{array}$ & $C_{t}=245.84 e^{-0.301 t}$ & $C_{t}=317.28 e^{-0.314 t}$ & $C_{t}=903.61 e^{-0.256 t}$ & $C_{t}=368.07 e^{-0.153 t}$ & $C_{t}=384.47 e^{-0.119 t}$ & $C_{t}=372.15 e^{-0.281 t}$ \\
\hline & half-life/day & $2.31^{c}$ & $2.21^{c}$ & $2.7^{c}$ & $4.53^{b}$ & $5.84^{a}$ & $2.47^{c}$ \\
\hline \multirow[t]{2}{*}{$\beta$ Cypermethrin } & $\begin{array}{l}\text { Dissipation } \\
\text { equation }\end{array}$ & $C_{t}=1.0586 e^{-0.227 t}$ & $C_{t}=1.2717 e^{-0.265 t}$ & $C_{t}=3.781 e^{-0.261 t}$ & $C_{t}=1.0529 e^{-0.176 t}$ & $C_{t}=1.7964 e^{-0.099 t}$ & $C_{t}=2.4196 e^{-0.143 t}$ \\
\hline & half-life/day & $3.05^{d}$ & $2.62^{d}$ & $2.66^{d}$ & $3.94^{c}$ & $7.01^{a}$ & $4.85^{b}$ \\
\hline Deltamethrin & half-life/day & $2.98^{c}$ & $2.63^{c}$ & $2.8^{c}$ & $3.66^{b}$ & $8.83^{a}$ & $3.88^{b}$ \\
\hline
\end{tabular}

Table 5. Initial deposits (significant level was $\alpha=0.05, n=3)$ of six pesticides in six leafy vegetables $(\mathrm{mg} / \mathrm{kg}$ )

\begin{tabular}{|c|c|c|c|c|c|c|}
\hline Matrix & Trichlorfon & Dimethoate & Chlorpyrifos & Chlorothalonil & $\beta$ Cypermethrin & Deltamethrin \\
\hline$\overline{\text { Cabbage }}$ & $35.4^{c}$ & $5.97^{c}$ & $6.7^{d}$ & $314.7^{c}$ & $1.21^{d}$ & $0.51^{d}$ \\
\hline Flowering Chinese cabbage & $66.7^{b}$ & $9.24^{c}$ & $8.89^{d}$ & $329.9^{b, c}$ & $1.43^{d}$ & $0.54^{d}$ \\
\hline Leaf mustard & $78.8^{a}$ & $18.84^{b}$ & $20.1^{a}$ & $674.1^{a}$ & $3.98^{a}$ & $1.71^{a}$ \\
\hline Water spinach & $45.8^{c}$ & $16.17^{b}$ & $12.08^{c}$ & $367.6^{b}$ & $2.16^{c}$ & $0.89^{c}$ \\
\hline Sweet potato leaves & $80.7^{a}$ & $23.44^{a}$ & $16.81^{b}$ & $359.1^{b}$ & $3.17^{b}$ & $1.30^{b}$ \\
\hline
\end{tabular}



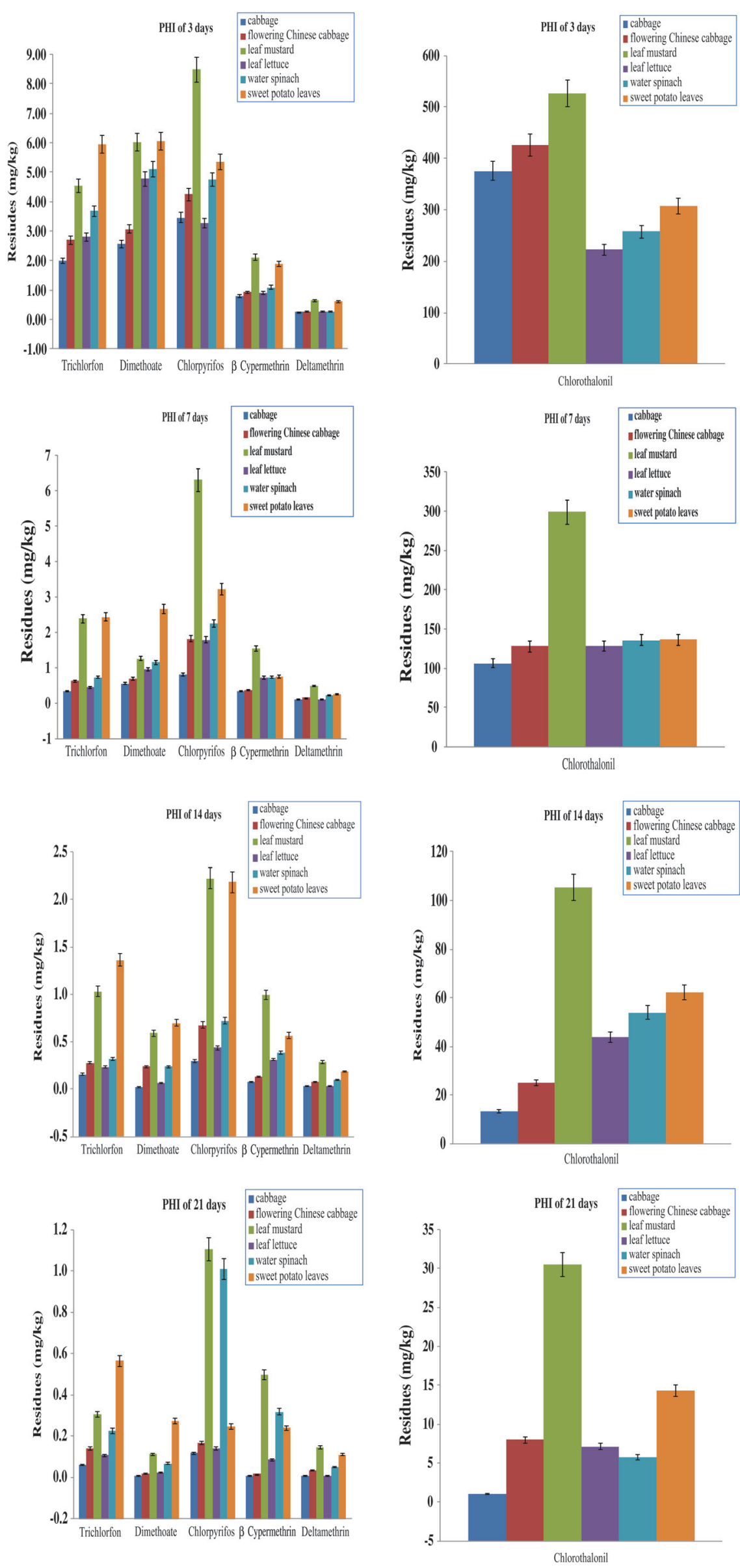

Figure 3. Terminal residues of six pesticides in six leafy vegetables at four PHIs 
Table 6. Terminal residues (significant level was $\alpha=0.05, n=3$ ) of six pesticides in six leafy vegetables

\begin{tabular}{|c|c|c|c|c|c|c|c|}
\hline PHI (days) & Matrix & Trichlorfon & Dimethoate & Chlorpyrifos & Chlorothalonil & $\beta$ Cypermethrin & Deltamethrin \\
\hline \multirow[t]{5}{*}{7} & Cabbage & $0.32^{b}$ & $0.54^{c}$ & $0.8^{d}$ & $106.3^{d}$ & $0.33^{c}$ & $0.1^{c, d}$ \\
\hline & Flowering Chinese cabbage & $0.61^{b}$ & $0.68^{c}$ & $1.81^{c, d}$ & $127.6^{c}$ & $0.35^{c}$ & $0.14^{c}$ \\
\hline & Leaf mustard & $2.38^{a}$ & $1.25^{b}$ & $6.29^{a}$ & $298.7^{a}$ & $1.54^{a}$ & $0.47^{a}$ \\
\hline & Water spinach & $0.72^{b}$ & $1.14^{b}$ & $2.24^{c}$ & $135.7^{b}$ & $0.72^{b}$ & $0.2^{b}$ \\
\hline & Sweet potato leaves & $2.43^{a}$ & $2.66^{a}$ & $3.20^{b}$ & $136.1^{b}$ & $0.74^{b}$ & $0.24^{b}$ \\
\hline
\end{tabular}

The superscript of $a, b, c$ and $d$ were the results of significant difference analysis.

PHI in leaf mustard were $6.29,298.7,1.54$ and $0.47 \mathrm{mg} / \mathrm{kg}$. In addition, the highest terminal residues were found on sweet potato leaves for trichlorfon and dimethoate, for the value was 2.43 and $2.66 \mathrm{mg} / \mathrm{kg}$. Moreover, like the results of initial deposition, leaf mustard and sweet potato leaves had the highest terminal residues for six pesticides in each subgroup, and the least terminal residues were detected on cabbage and leaf lettuce for six pesticides in each subgroup. The analysis of terminal residual data at PHIs of 3 days, 14 days, and 21 days was similar to the data of 7 days PHI, and the highest terminal residues were also found on leaf mustard and sweet potato leaves. It might be affected by some physical and chemical factors, climatic condition, soil characteristics, and microorganisms.

This result shows that the highest terminal residues were found on leaf mustard and potato leaves for six pesticides at four PHIs, while the cabbage and leaf lettuce had least terminal residues. In other words, the rule of terminal residues was similar to initial deposition and maximum residues.

3.6. Classification of six leafy vegetables commodities. Similar residue levels and morphology for commodities can be classified as a commodity group or subgroup [6]. To select representative commodity from group or subgroup, half-life, highest initial deposits, maximal residues, and terminal residues at four PHIs would be the most important factors. The significant difference (significant level was $\alpha=0.05, n=3$ ) of half-life, highest initial deposits, and terminal residues (7 days PHI) was analyzed by SPSS (Duncan) for six pesticides in six leafy vegetables. The results are listed in Tables 4 to 6 .

In China, cabbage or kale was selected as representative commodity in head and stem brassica vegetables. While spinach was selected as representative commodity in leafy green subgroup vegetables. In this study, leaf lettuce, water spinach, and sweet potato leaves were classified in leafy green vegetable subgroup. And they have obvious rules to follow in contrast with other vegetables. Sweet potato leaves had the highest initial deposits, maximal residues, and terminal residues for six pesticides. In comparison of half-life and terminal residues of the same vegetable subgroup for $60 \%$ pesticides, leaf lettuce, water spinach, and sweet potato leaves had significant difference. The highest initial deposits and maximal residues of leaf lettuce, water spinach, and sweet potato leaves had significant difference for $80 \%$ pesticides. Thus, sweet potato leaves might not be suitable to be classified in leafy green vegetable subgroup. This conclusion is the same as crop classification of China.

Cabbage, flowering Chinese cabbage, and leaf mustard were classified in head and stem brassica vegetable subgroup. And they also have obvious rules to follow in contrast with other vegetables. Leaf mustard has the highest initial deposits, maximal residues, and terminal residues for six pesticides in the same subgroup. Significant difference was found on cabbage and flowering Chinese cabbage by comparing with the highest initial deposits, maximal residues, and terminal residues for six pesticides. However, there was no significant difference between cabbage and flowering Chinese cabbage (except for trichlorfon and dimethoate). The half-life of leaf mustard, cabbage, and flowering Chinese cabbage had no significant difference, except for the half-life of cabbage which was relatively higher on dimethoate and chlorpyrifos. This result is contrary to the research of
Reynolds et al. [4] and Yu et al. [6]. For the research of Reynolds and $\mathrm{Yu}$, cabbage had the highest initial deposits in different pesticides, and cabbage was selected as the representative commodity. Their result was similar with crop classification of China. However, in this study, leaf mustard can be selected as the representative commodity in the same subgroup. In addition, this conclusion is different from crop classification of China.

Therefore, sweet potato leaves might not be suitable to be classified in leafy vegetable subgroup. Leaf mustard can be selected as representative commodity in the same subgroup without regard to dietary intake and dietary habits.

\section{Conclusion}

The method applied to extraction, purification, and estimation of residues was found to be satisfactory for both quantitatively and qualitatively. Average recovery of six pesticides in six leafy vegetables was in the range of $81 \%-119 \%$ at three spiked levels with $0.01 \mathrm{mg} / \mathrm{kg}, 0.05 \mathrm{mg} / \mathrm{kg}$, and $0.5 \mathrm{mg} / \mathrm{kg}$. The relative standard deviations (RSDs) were in the range of $1 \%-14 \%$. From the result of residues in supervised field trials in Guangxi sites, it was found that the highest terminal residues, initial deposits, and maximum residues were detected on leaf mustard and sweet potato leaves for six pesticides after application, while the least terminal residues, initial deposits, and maximum residues for six pesticides were found on cabbage and leaf lettuce. It should be pointed out that the trials were conducted only at one site in this study and dietary risk assessment should be taken. The dietary risk assessment of six pesticides in six leafy vegetables will be drawn into our further research. Guangxi belongs to the subtropical monsoon climate zone; this means that the study results may only be suitable for similar climate zones, and more field experiment of pesticides in other climate zones was needed to be further studied. Leaf mustard and sweet potato leaves had the highest residues of trichlorfon, dimethoate, chlorpyrifos, chlorothalonil, $\beta$ cypermethrin, and deltamethrin on six leafy vegetables in supervised field trials. However, leaf lettuce, water spinach, and sweet potato leaves had significant difference in all six pesticide residues. Therefore, sweet potato leaves might not be suitable to be classified in leafy vegetable subgroup. Leaf mustard can be selected as representative crop in leafy vegetables, and this conclusion should be considered as a complement on crop classification of China.

\section{Conflict of interest}

The authors declare no financial or other conflicts of interest.

Acknowledgment. This work was supported by National Key R\&D projects of comprehensive evaluation and optimization of environmental effects of chemical fertilizers and pesticides in tea garden (No. 2016YFD0201208-4) and Guangxi Key Laboratory Cultivation Base of Agro-Environment and AgroProduct Safety $(2016,133)$.

\section{References}

1. Han, Y. T.; Zou, N.; Song, L.; Li, Y. J.; Qin, Y. H.; Liu, S. W.; Li, X. S.; Pan, C. P. J. Chromatogr. B. 2015, 1005, 56-64.

2. Han, Y. T.; Song, L.; Zhao, P. Y.; Li, Y. J.; Zou, N.; Qin, Y. H.; Li, X. S.; Pan, C. P. Food Chem. 2016, 197, 730-736. 
3. Park, J.; Mamun, M. I. R.; El-Aty, A. M. A.; Choi, J.; Im, G.; Oh, C.; Shim, J. Korean J. Pestic. Sci. 2009, 13, 28-38.

4. Reynolds, S. L.; Fussell, R. J.; Macarthur, R. Food Addit. Contam. 2005, 22, 31-38

5. Yu, C. S.; Fan, S. F.; Li, Y. J.; Zou, N.; Li, X. S.; Pan, C. P. Int. J. En. An. Chem. 2015, 95, 419-433.

6. Qin, Y. H.; Zhang, J. R.; Zhang, Y.; Li, F. B.; Han, Y. T.; Zou, N.; Xu, H. W.; Qian, M. Y.; Pan, C. P. J. Chromatogr. A. 2016, 1462, 19-26.

7. Viazis, S.; Akhtar, M.; Feirtag, J.; Diez-Gonzalez, F. Food Microbiol. 2011, 28, 149-157.

8. Fan, S. F.; Zhang, F. Z.; Deng, K. L.; Yu, C. S.; Liu, S. W.; Zhao, P. Y.; Pan, C. P. J. Agric. Food Chem. 2013, 61, 2039-2044.

9. Liu, C.; Hofstra, N.; Franz, E. In. J. Food Microbiol. 2013, 163, 119-128.

10. Announcement No. 1490th of the Ministry of agriculture of the People's Republic of China.

11. EPA e-CFR data, $\$ 180.41$ Crop group tables. https://www.ecfr.gov/cgibin/text-idx?SID=46e 0f15c31b8f5b1c0a348eac9f380e5\&mc=true\&node=se40.24.180 $141 \&$ rgn $=$ div8.

12. Commission regulation (EC) No. 178/2006. Amending Regulation (EC) No. 396/2005 of the European Parliament and of the Council to establish. Annex I listing the food and feed products to which maximum levels for pesticide residues apply.

13. Li, Z. A.; Pan, C. P.; Song, W. C.; Shan, W. L.; Ye, J. M. Pestici. Sci. Admin. 2011, 30, 40-45.

14. CCPR. Food and Agriculture Organization, World Health Organization Report of the 45 session of the Codex Commit-tee on pesticide residues Xian, China, 2013.
15. Mercanoglu Taban, B.; Halkman, A. K. Anaerobe 2011, 17, $286-287$.

16. Fan, S. F.; Deng, K. L.; Yu, C. S.; Zhao, P. Y.; Bai, A. J.; Li, Y. J.; Pan, C. P.; Li, X. S. J. Agric. Food Chem. 2013, 61, 9036-9044.

17. Guimarães, A. T. B.; Silva De Assis, H. C.; Boeger, W. Ecotox. Environ. Safety 2007, 68, 57-62.

18. Anwar, S.; Liaquat, F.; Khan, Q. M.; Khalid, Z. M.; Iqbal, S. J. Hazard. Mater. 2009, 168, 400-405.

19. Saafi, E. B.; Louedi, M.; Elfeki, A.; Zakhama, A.; Najjar, M. F.; Hammami, M.; Achour, L. Exp. Toxicol. Pathol. 2011, 63, 433-441.

20. Zhang, C.; Wang, S.; Yan, Y. Bioresource Technol. 2011, 102, 7139-7146.

21. Stevenson, B. J.; Bibby, J.; Pignatelli, P.; Muangnoicharoen, S.; O Neill, P. M.; Lian, L.; Müller, P.; Nikou, D.; Steven, A.; Hemingway, J.; Sutcliffe, M. J.; Paine, M. J. I. Insect Biochem. Mol. Biol. 2011, 41, 492-502.

22. Affam, A. C.; Chaudhuri, M. J. Environ. Manage. 2013, 130, $160-165$.

23. Institute for the Control of Agrochemicals Standard operating procedures on pesticide registration residue field trials Standards Press of China, Beijing, China, CN, 2007.

24. Ministry of Agriculture of the People's Republic of China NY/T7882004 Guideline on pesticide residue trials Standards Press of China, Beijing, China, CN, 2004.

25. Ministry of Agriculture of the People's Republic of China NY/T761-2008 Determination of vegetables and fruits in organophosphorus, organochlorine, pyrethroid and carbamate pesticide residues Standards Press of China, Beijing, China, CN, 2008. 